\title{
An introduction to A Research Agenda for Event Impacts
}

\section{Nicholas Wise}

Researchers who focus on event studies or event management seek ways to explore how events impact on places, communities, and the environment (Armbrecht et al., 2019; Getz and Page, 2020; Maguire, 2020; Mair, 2019; Preuss, 2007b; Rojek, 2013; Wise and Harris, 2017, 2019). Events research draws inspiration from and builds on a wide range of interdisciplinary approaches across the social sciences, physical sciences, arts and humanities, and business and management literatures (see Andrews and Leopold, 2013; Van Niekerk, 2017). Events today play a key role in planning and development decisions, and they contribute to image formation and place brands, because in many cases when an event is hosted, people recognize the event and use it to associate it with places (Cudny, 2020; Hahm et al., 2019). All events have or create an impact, which leaves an impression on people, places, and/or environments. The timeliness of this book is a chance to reflect on how different experiences are measured and managed (Biaett and Richards, 2020).

Scales of events and types of events are vast, and no matter the size or purpose of an event, the aim is to unite people through mutual interests to share an experience (see Kim and Dombrosky, 2016; Wise, 2020a). Given events is a vast industry, some argue that a one-size-fits-all approach is not appropriate in events studies and thus each event must be evaluated based on the specific impacts that it creates: on the local environment, for the local community, and what it contributes to the local economy. Given this local consideration, both internal and external forces create impacts that challenge researchers to look at wider trends and patterns that refer us to local-global, local-national, or localregional trends, issues, and considerations. This is also why it is essential that researchers avoid generalizations and seek ways to assess event impacts from various theoretical lenses, management perspectives, or planning principles, so that various perspectives are recognized and realized and impacts are explored and evaluated holistically. 
This book, as part of Elgar Research Agendas, contributes insight into contemporary scholarship on ways of exploring and approaching event impacts. A key intention of this book is to show the links between theory and practice by pointing scholars, practitioners, and students to research directions and critical considerations that need to be addressed when studying events and the impacts that events create. A widely used quote by Allen et al. $(2010,60)$ just over a decade ago now still points us to the fact that "events do not take place in a vacuum [and] they touch almost every aspect of our lives". These aspects involve social, cultural, economic, environmental, and political considerations and directives that can influence decisions and policies in various ways (Fredline et al., 2003; Holmes et al., 2015). Researchers have sought ways to explore relationships across these impacts, but this can and still does represent challenges given directives and interests need to be agreed among various stakeholders (see Maguire and McLoughlin, 2019). Critically, many decisions are based on the economic value that an event can bring to a place, and these values can in many cases be speculative. Therefore, what is essential when events are being planned and organized is to ensure an event is monitored and managed in a way that considers these overlapping considerations so that true and wider impacts are identified.

Whether an event is worth staging will depend on who and what is being impacted. Similar to Musgrave and Raj (2009), Allen et al. (2010) point to social, environmental, and economic concerns as the three pillars of event impacts. Bladen et al. (2018) point to who is affected by events, and categorize based on personal impacts, organizational impacts, and external impacts to showcase that events can impact individuals, influence decisions and directions for organizations, and contribute to external dimensions that direct change and collaborations. People who attend events or live in a place hosting an event will have different experiences, and these may be positive or negative; this can also shape event legacies (Agha et al., 2012). This will depend on one's ability to attend, participate, or engage in the experience of an event, but ways of planning and critical scholars point researchers to issues concerning inclusion and exclusion (Cowan, 2016; Duignan et al., 2019). Organizations are involved in organizing and/or hosting events or invest in events because they are seeking reputation and profit. Then there are the external impacts that Musgrave and Raj (2009) speak to based on interactions between those engaged in the events industry and what events contribute to the economy, what events do to the environment, or how events embrace people, cultures, and society.

The scale and duration of an event will more or less show the extent of an event's impact, and depending on how successful an event was or how it was 
received will either extend event impacts or limit impacts going forward. With any event lifecycle there are the pre-, during, and post-event phases (Gellweiler et al., 2018; Holmes and Ali-Knight, 2017), or initiation, planning, implementation, event, and closure phases as highlighted in Bladen et al. (2018). A lot of research has addressed these different phases independently, so calls for more longitudinal approaches will allow researchers to understand the different extents of impacts at these different stages. Studies that focus on the bidding stage seek to gain insight into support, awareness, and attitudes towards hosting an event (see Richards and Marques, 2016; van der Steen and Richards, 2019). A lot of pre-event studies conducted just prior to an event being held are about understanding the vision of event impacts and how well managing authorities are planning and preparing (e.g. Wise et al., 2021). Studies conducted during an event tend to focus on delivery, and because the focus is placed on operations and the spectacle of the event itself, this can distract from underlying social problems or environmental issues that an event is causing (see Mooney et al., 2015). Post-event is another crucial time to explore not just the aftermath of an event but also whether promises were kept and to begin analyzing legacies to understand if the costs and benefits of hosting are resulting in new opportunities locally and financially secure futures for the host destination (Maharaj, 2017; Wise, 2019). Bladen et al. (2018) break this down from short- to long-term impacts, noting the immediate post-event period ( $0-2$ years), intermediate post-event period ( $2-5$ years), and legacy period ( 5 years and longer). A challenge with post-event research is it cannot be rushed and many studies need to reflect on events over a decade after they were held to fully understand the impact of an event (see García, 2005).

Important to note is that longitudinal research is not just concerned with a single event lifecycle, but can explore trends and happenings each year for events that are held annually (see Wise et al., 2015). Event impacts can and will differ based on the timing of an event (time of day or year, season), duration (a short-term event that lasts a few hours or a long-term event which takes place over several weeks or across a calendar year), visibility (exposure in the media or projects that brought about tangible change to the landscape), and the type of event (weddings or local celebrations, cultural events, music festivals, or sporting events). The stakeholders involved also have very different experiences and their reactions require consideration over time. Those involved with policy decisions, strategy, investing, and the supply side bring influence from the top, and position change in a way that they see as being beneficial based on the visions and objectives that will result in desired outcomes that are also sustainable (Ziakas, 2019). There are also consumers, and the ability to keep up with and meet consumer demand will ensure that they are satisfied with an event product. A key consideration here is that top-down actors who work to 
deliver visions and visitors to the event often only play temporary roles, but it is the local community and residents who see and experience the full lifecycle of an event or see how an event changes and grows year after year. Local residents, then, are the stakeholders who are continually impacted over time. The local and surrounding environment may take/suffer the burden of events, but finances may be a lot more fluid and flow in and out of the host destination.

Important to any event is community participation and support among all stakeholders. Improving access and promoting equitable futures requires the input and involvement of the local population. Event planners will look to use different techniques, promotion strategies, or methods to encourage participation, but they need local residents to want to get involved. According to Wise et al. $(2021,54)$, "when people are not satisfied with urban planning agendas there is a chance they may disengage, and therefore not be aware of future events/activities". To overcome this issue and to help engage residents, Richards (2017, p. 9) mentions the need for "more proactive use of events in order to drive a wide range of different policy agendas". Waitt (2003) found that seeking ways to also unite locals through events helps create a new or renewed sense of belonging, and Zhao and Wise (2019) add that a key consideration is how enthusiastic locals feel when they are at an event. Concerning involvement and enthusiasm, researchers have found links between the quality of information provided and levels of enthusiasm towards an event or attraction (see Camacho et al., 2019). This also can involve how satisfied people are with how an event is impacting the environment. Some argue that events and environmental sustainability may be a contradiction in terms; for planners who want to maximize the financial success of an event a key focus still requires recognizing and dedicating efforts to minimize negative environmental impacts. Hanrahan and Maguire (2016) present provisions to ensure the environment is protected. Protecting the environment and ensuring the community is involved is an attempt to work towards financially secure and eventful futures.

The point at the end of the last paragraph directs readers to three key areas concerning event impacts: legacy, sustainability, and regeneration. Legacy, according to Preuss (2007a), involves a number of dimensions, planned or unplanned, negative or positive, and tangible or intangible. Scholars who have classified legacies address economics, social, and environmental legacies, but also infrastructure, changes to public life, politics, and culture, and symbols, memories, and history (Cashman, 2005). From a legacy standpoint, places seek to sustain gains from investments put into an event, use the event to market destinations, sustain positive aspects of an event's image, and understand how an event changed or improved the local quality of life (Karakadis and Kaplanidou, 
2012). Moreover, event impacts and legacies look at ways of increasing capital, whether this be economic (assets, investments, profits), social (social networks to encourage action and activity), physical (infrastructural, landscape change), symbolic (prestige, new recognition), cultural (knowledge, skills, education), or human (improvements to people's livelihoods, new skills or expertise).

Pertinent and related to discussions of legacy is sustaining impacts over time, through policies that work towards more inclusive and equitable futures (Finkel, 2015), increasing place competitiveness (Aquilino et al., 2019), or putting in place protective measures for the environment (Hanrahan and Maguire, 2016). The key focus is on maximizing benefits and minimizing negative impacts, all the while putting emphasis on supporting communities and protecting resources (Getz, 2013). Academics, policy makers, and planners addressing critical directions and issues related to sustainability are often influenced by the 2030 United Nations Sustainable Development Goals. Recent work in tourism has provided some directions (Boluk et al., 2019), and these are also relevant in event studies and management research. A number of chapters in this book focus on legacy from various standpoints; informing stakeholders of these and ensuring they are aware of legacy initiatives is essential.

The regeneration or redevelopment of spaces and places is a key contributor of event impacts, especially in terms of how impacts are understood and envisioned (Wise and Harris, 2017), as new developments focus on expanding event portfolios in a destination (Ziakas and Costa, 2011). Changing and altering spaces for events can have social, economic, and environmental consequences, especially when it comes to tangible developments. Moreover, regeneration initiatives are part of wider regional and urban policy agendas to "upgrade" places and create eventful futures (Smith, 2012), whether this is linked to place images or changing economic bases (Wise and Harris, 2017). However, Roberts $(2017,9)$ adds that "regeneration is not solely a reaction to changed circumstances. In some instances regeneration is proactive and seeks either to avoid an emerging problem, such as the consequences of decline of a basic industry, or to improve the prospects of a particular neighborhood." Scholars have addressed three recognized types of event-influenced regeneration strategy: event-led regeneration, event-themed regeneration, and event-added regeneration (Bladen et al., 2018; Evans, 2019; Sadd, 2010; Smith and Fox, 2007). Looking at these considerations, event-led regeneration puts events at the center of regeneration efforts, with events and the venues built acting as catalysts for development and branding, which can also be considered a flagship approach (Wise and Harris, 2017). Event-led regeneration includes reusing brownfields or industrial lands and repurposing these areas 
for events (Holmes et al., 2015). Considering event-themed regeneration, this is where events are just a part of a wider strategy (or a lever approach), whereby events contribute to policy and intentions to host events (Bladen et al., 2018). Event-added regeneration is when events are not fully leveraged for regeneration purposes, which can be a showcase approach to define the changes made (Bladen et al., 2018).

This book includes 19 chapters, organized into three parts. In events research, a lot of consideration is placed on sport, and while this book includes cases and insights on sport, it also looks to include examples from a range of different event types. Part I includes three chapters that outline the theory and concepts that align with economic, environmental, and social impacts of events. Part II includes 12 chapters that present a range of research themes and examples. Each chapter starts by introducing a research area and reviews work and conceptual directions concerning an area of research. The chapters then move on to present a case example to show and discuss the work in this area, before finishing with a discussion of future directions of research, which helps position both theoretical and practical avenues that need consideration. Part III includes three chapters that focus on going forward in event impacts research, pointing to legacy and sustainability and the need for continued assessment so that event impacts are not just descriptively overviewed but also critically evaluated.

Part I addresses the three impacts recognized in triple-bottom-line considerations of sustainability (Dwyer, 2005; Hede, 2007; Wise, 2020b). This part begins with Larry Dwyer's chapter, "Economic impacts of events". Dwyer overviews approaches that researchers consider, focusing on standard economic impact analysis, computable general equilibrium modeling, and cost-benefit analysis. Dwyer has published extensively on the economic impacts of events and tourism (see Dwyer, 2019; Dwyer et al., 2004, 2005). In this chapter, Dwyer addresses how different stakeholders benefit from these analysis techniques and how policy makers use data to inform decisions. Evaluating economic impacts results in understanding economic returns and where to invest in the future. This approach is persuasive and guides future decision making based on tangible results and secured outcomes. In Chapter 3, Kelly Maguire considers the growth of the events industry and how this puts additional stress and pressure on the environment. Some of the approaches that Maguire outlines are environmental impact assessments, strategic environmental assessment, models for sustainable event management, global criteria, and indicator systems. Taking a planning focus, Maguire categorizes environmental impacts and critically overviews responses and management approaches. This chapter builds on and is informed by her work on environmental impacts and local 
authority planning (see Hanrahan and Maguire, 2015; Maguire, 2020; Maguire and McLoughlin, 2019). Chapter 4 by Nicholas Wise, Susanne Gellweiler, and Enqing Tian moves on to discuss events and social impacts, challenging scholars to consider intangible approaches and critical directions concerning research in and with local communities. Wise et al. present a range of perspectives from the literature and address key questions and social conditions that researchers can take forward in social impact studies. The authors of this chapter assess the social impacts of events across numerous cases and discuss a number of conceptual directions (see Gellweiler et al., 2018, 2019; Tian, 2017; Tian and Wise, 2020; Wise, 2019).

Part II, "Research themes and case examples", focuses on a range of contemporary topics and issues with cases to put each research area into perspective. In Chapter 5, Jeeyeon Jeannie Hahm focuses on convention events. Conventions and business events are the most common types of events and destinations that regularly host events in their venues are looking to expand operations and host capacities in modern venue complexes. Hahm provides insight from Orlando, discussing the importance of the Orange County Convention Center and how this venue has not only expanded but adapted to host safe events during the Covid-19 pandemic. Hahm has also published research on convention attendees (Hahm et al., 2016).

Another popular type of events and an area that is rapidly expanding is sports tourism. Marko Perić, Jelena Đurkin Badurina, and Nicholas Wise focus on sports tourism and event impacts in Chapter 6. Sports events tourism is experiencing growth and leading to competition between destinations to attract and host such events. Perić et al. look at the Risnjak Trail running events in Gorski kotar, Croatia as an example of how sports tourism is being developed to expand event opportunities and experiences in this part of the country. Building on their prior work on events and sports tourism, an important impact here is developing the region and helping overcome seasonality (see Wise et al., 2019).

Chapter 7 focuses on religious events and commercialization. Flávia Ulian and Angela Fileno are concerned with cultural and religious events and the importance of embedded histories. In this chapter Ulian and Fileno focus on the Lavagem do Bonfim and a devotion to which there has been a festival dedicated since the nineteenth century in Salvador, the capital city of Bahia in Brazil. The authors provide a number of directions on aspects of heritage and pilgrimage surrounding how events create wider social and cultural impacts. While this chapter is based on a new project on which the authors are collaborating, their published work has addressed related insight on how events 
impact on communities. Ulian has looked at how events impact on people locally (see Ulian and da Silva, 2020), looking at these impacts from a different event context, while Fileno has looked at history and heritage and how colonialism impacts on communities (see Fileno, 2019).

Chapter 8 by Takamitsu Jimura builds on conceptual insights from Chapter 7 and looks at more contemporary events based on intangible cultural heritage. Jimura's chapter provides directions on the impact of heritage and builds on developments from a recent monograph (see Jimura, 2018). This chapter discusses UNESCO principles to guide the importance of research, first focusing on the intangible cultural heritage convention before presenting a case example of fireworks (hanabi) and fireworks displays (hanabi-taikai) in Japan which have been a tradition and form of entertainment in the country since the seventeenth century. The event impact considerations refer to social and economic impacts, but do point to the need to focus on environmental sustainability as well.

Jada Lindblom presents "Transformational atmospheres of international sporting events" in Chapter 9. The focus on "atmospheres" and events is influenced by scholarship from cultural geography to attract people to experience activities that connect people with a place. After discussing conceptual directions on affective atmospheres, Lindblom moves on to present initial findings from the Red Bull Cliff Diving World Series, a popular event held in the city of Mostar, Bosnia and Herzegovina. A range of community impacts are discussed and the chapter includes insights from a resident survey and subsequent interviews with those attending the event. Lindblom addresses the need to focus on co-production as this can enhance experiences of those attending and participating in events. This chapter was developed alongside Lindblom's dissertation work on tourism in Mostar, Bosnia and Herzegovina (see Lindblom et al., 2020).

Research on sporting events often focuses on the context of development in urban areas. In Chapter 10, Lucia Aquilino focuses on rural events and social development to provide a perspective on events in rural locales. This study offers some critical directions that build on and relate to prior research focusing on the World Alternative Games, an event that takes place in Britain's smallest town, Llanwrtyd Wells. The event is known for its wacky approach and was developed to promote rural tourism in this remote part of Wales (see Aquilino et al., 2020, 2021). While Chapter 9 addressed a sense of community, placemaking, and rural destination marketing, this chapter is concerned with social development and how events contribute to new community identities which are embraced and contested. A key takeaway from this chapter is the 
need to focus not only on community development, but also on fostering and encouraging participation.

In Chapter 11, "Local authority planning, sustainability, and event governance", Kelly Maguire discusses how local authorities play an important role when it comes to overseeing all aspects of events, and must work with communities to ensure that events are socially, economically, and environmentally sustainable. Maguire provides directions in this area, which is important at the local authority level to ensure event planning is sustainable and meets the needs of those impacted (see Maguire, 2019), and is also critical of shortcomings when it comes to planning and managing events locally. This chapter presents insights from Ireland and addresses approaches locally while acknowledging national directions that are shaping new policies to put in place so that impacts are maximized and move towards securing sustainable futures.

Chapter 12 on the impact of events on place branding by Waldemar Cudny presents geographical insights building on theoretical perspectives of space and place. Events are playing an increasingly important role when it comes to marketing places at different scales, from the nation or region to local destinations. The growth of events has also resulted in increased competition and this is challenging planners to devise unique brands that reflect the identity of places and create recognition so that tourism opportunities will build following the hosting of events. In this chapter, Cudny presents the case of Euro 2012, where one of the host cities for this event was Gdansk, Poland. The author looks at different dimensions, paying attention to media messages (referring to image spaces) and event experiences, each contributing to an impression of a place. Cudny presents directions and relates to a number of recent findings from a book he recently edited (see Cudny 2020).

"Mega-event trends and impacts" by Tara Fitzgerald and Brij Maharaj, Chapter 13, focuses on event hosting in emerging economy nations, with specific emphasis on the BRICS (Brazil, Russia, India, China, and South Africa) as these countries are seeing increased attention within mega-event hosting trends (see Maharaj, 2015; Wise, 2020a). The authors begin the chapter by overviewing insights on mega-events and looking at recent hosts among the BRICS nations. They then look at critical perspectives and different political structures and refer to issues that emerged during the bidding process and time of hosting, which saw funds poured into infrastructures and directed away from social programs, addressing not only general challenges and points of critique and protest, but also concerns around human rights violations, types of resistance tactics, and future concerns. 
The postponement of events is the focus of Chapter 14 by Alexander Bond, Daniel Parnell, and Jan Andre Lee Ludvigsen. This chapter reflects the current state of events directly impacted by the Covid-19 pandemic. Numerous events and mass gatherings at all scales have been impacted, with many being cancelled or postponed. While sporting events are directly impacted, other types of events have since moved operations online until gatherings are once again considered safe. For instance, the postponement of the Tokyo Olympics 2020 to 2021 had major economic and financial implications, as did the postponement of UEFA Euro 2020 to 2021. This chapter on postponement relates to their recently published work on events and the Covid-19 pandemic that considers directions for sport event planners and managers (see Ludvigsen and Hayton, 2020; Parnell et al., 2020). The authors address the need for flexibility, while acknowledging that postponement represents a range of knock-on challenges and issues when it comes to financial commitments, securing investments, and logistical issues surrounding planning and organizing.

Chapter 15, "Disability, access, and inclusion" by Erin Pearson and Laura Misener uses the example of parasport events and the growth of these events, where there are a number of tensions surrounding access and inclusion. Pearson and Misener begin by outlining guidelines around accessibility and inclusion at events with a focus on social legacies, addressing insights from recent research on parasport (see Misener et al., 2020). Event legacy and leveraging is a conceptual focus that the authors build on, and the examples referred to in this chapter are the Ontario Parasport Legacy Group and the 2015 Pan/ Parapan American Games. In the Canadian province of Ontario, objectives were set to increase the participation of persons with disability, the number of parasport coaches, awareness of parasport, and work towards increasing the implementation of accessibility standards in sport/recreation facilities. Pearson and Misener address the approaches, strategies, and challenges that emerged and point to a number of informed recommendations going forward.

Chapter 16 by Judith Mair discusses events and climate change. Climate change is a pressing issue, with climate action being one of the 17 United Nations Sustainable Development Goals, and nations and organizations are working to find solutions to combat climate change as this will have implications that can negatively impact our economy and society. Mair considers recent developments and explores this critical and contemporary topic, building on insights published a decade ago (see Mair, 2011). Some critical directions that Mair points to in this chapter are resilience, mitigation, and adaptation. Mair presents and discusses different types of events that are most affected by climate change impacts and points to a number of critical research 
directions, addressing links across policy and practice by discussing important policy and stakeholder implications.

The final three chapters of the book present some directions going forward with event impact research. Chapter 17, "Evaluating cultural legacy: From policy to engaged research" by Rafaela Neiva Ganga, focuses on reconciling policy and evaluating events, focusing attention on the evaluation of Liverpool as the European Capital of Culture in 2008 and 2018. Ganga also considers events and different scales, discussing boroughs of culture events held in Liverpool and London. This chapter provides insight on how legacy is maximized through evaluation and the need to address a wide range of event impacts. Chapter 18 by Kylie Wasser, Landy Di Lu, and Laura Misener addresses legacy and lasting impacts through a systematic review of evidence on different types of organizational forms used for legacy delivery. This work provides directions on this topic from sport development and governance standpoints (see Misener and Lu, 2020; Misener and Wasser, 2016). The directions offered are written for a number of stakeholders in the hope that collaboration opportunities can be recognized so as to maximize future impacts. "Concluding remarks and event impacts going forward" by Kelly Maguire provides a brief conclusion that summarizes critical points from the book and puts future event impacts research into perspective.

Key considerations involve exploring, interpreting, and realizing impacts and require researchers to keep an open mind and be critical of who benefits from hosting events. A focus on event impacts and the wider benefits that events create see researchers focus on issues surrounding sustainability, the need to define legacies, and the extent that regeneration efforts focus on events as places seek to change to gain a competitive advantage, secure economic futures, work towards protecting the environment, and ensure socially sustainable futures.

\section{References}

Agha, N., Fairley, S., and Gibson, H. (2012), Considering legacy as a multi-dimensional construct: The legacy of the Olympic Games, Sport Management Review 15(1), 125-139.

Allen, J., O’Toole, W., Harris, R. and McDonnell, I. (2010), Festival and Special Event Management, Wiley, Oxford.

Andrews, H. and Leopold, T. (2013), Events and the Social Sciences, Routledge, London. 
Aquilino, L., Armenski, T. and Wise, N. (2019), Assessing the competitiveness of Matera and the Basilicata Region (Italy) ahead of the 2019 European Capital of Culture, Tourism and Hospitality Research 19(4), 503-517.

Aquilino, L., Harris, J., and Wise, N. (2021), A sense of rurality: Events, placemaking and community participation in a small Welsh town, Journal of Rural Studies 83, $138-145$.

Aquilino, L., Wise, N., and Harris, J. (2020), Wackiness and event management: The case of the World Alternative Games, Event Management 24(5), 567-577.

Armbrecht, J., Lundberg, E., and Andersson, T.D. (eds) (2019), A Research Agenda for Event Management, Edward Elgar, Cheltenham, UK and Northampton, MA, USA.

Biaett, V. and Richards, G. (2020), Event experiences: Measurement and meaning, Journal of Policy Research in Tourism, Leisure and Events 12(3), 277-292.

Bladen, C., Kennell, J., Absom, E., and Wilde, N. (2018), Events Management: An Introduction, Routledge, London.

Boluk, K.A., Cavaliere, C.T., and Higgins-Desbiolles, F. (2019), A critical framework for interrogating the United Nations Sustainable Development Goals 2030 Agenda in tourism, Journal of Sustainable Tourism 27(7), 847-864.

Camacho, D.P., Alonso Dos Santos, M., and Duclos Bastias, D. (2019), The relationship between factors that contribute to support and future intentions in relation to a major sporting event, Academia Revista Latinoamericana de Administración 32(4), 442-454.

Cashman, R. (2005), The Bitter-Sweet Awakening: The Legacy of the Sydney 2000 Olympic Games, Walla Walla Press, Sydney.

Cowan, A. (2016), A Nice Place to Visit: Tourism and Urban Revitalization in the Postwar Rustbelt, Temple University Press, Philadelphia, PA.

Cudny, W. (ed.) (2020), Urban Events, Place Branding and Promotion, Routledge, London.

Duignan, M.B., Pappalepore, I., and Everett, S. (2019), The "summer of discontent": Exclusion and communal resistance at the London 2012 Olympics, Tourism Management 70, 355-367.

Dwyer, L. (2005), Relevance of triple bottom line reporting to achievement of sustainable tourism: A scoping study, Tourism Review International 9(1), 79-93.

Dwyer, L. (2019), Economic assessment of special events: A perspective article, Tourism Review 75(1), 191-193.

Dwyer, L., Forsyth, P., and Spurr, R. (2004), Evaluating tourism's economic effects: New and old approaches, Tourism Management 25(3), 307-317.

Dwyer, L., Forsyth, P., and Spurr, R. (2005), Estimating the impacts of special events on an economy, Journal of Travel Research 43(4), 351-359.

Evans, G. (ed.) (2019), Mega-Events: Placemaking, Regeneration and City-Regional Development, Routledge, London.

Fileno, A. (2019), A terceira geração de brasileiros em Lagos. Moisés da Rocha e as fissuras da dominação colonial, Anos 90 26, 1-20.

Finkel, R. (2015), Introduction to special issue on social justice and events-related policy, Journal of Policy Research in Tourism, Leisure and Events 7(3), 217-219.

Fredline, L., Jago, L., and Deery, M. (2003), The development of a generic scale to measure social impacts of events, Event Management 8, 23-37.

García, B. (2005), Deconstructing the city of culture: The long-term cultural legacies of Glasgow 1990, Urban Studies 42(5/6), 841-868. 
Gellweiler, S., Fletcher, T., and Wise, N. (2019), Exploring experiences and emotions sport event volunteers associate with "role exit", International Review for the Sociology of Sport, 54(4), 495-511.

Getz, D. (2013), Event Tourism: Concepts, International Case Studies, and Research, Cognizant Communication Corporation, Putnam Valley, NY.

Gellweiler, S., Wise, N., and Fletcher, T. (2018), Understanding the "lived experience" of sport event volunteers: Using the hermeneutic circle as a guiding conceptual framework, Event Management 22(4), 629-642.

Getz, D. and Page, S. (2020), Event Studies: Theory, Research and Policy for Planned Events, Routledge, London.

Hahm, J., Breiter, D., Severt, K., Wang, Y., and Fjelstula, J. (2016), The relationship between sense of community and satisfaction on future intentions to attend an association's annual meeting, Tourism Management 52, 151-160.

Hahm, J., Tasci, A.D.A., and Breiter Terry, D. (2019), The Olympic Games' impact on South Korea's image, Journal of Destination Marketing and Management 14, 100373.

Hanrahan, J. and Maguire, K. (2015), Local authority planning provision of policies and guidelines for event management: An Irish perspective, International Journal for Responsible Tourism 4(2).

Hanrahan, J. and Maguire, K. (2016), Local authority provision of environmental planning guidelines for event management in Ireland, European Journal of Tourism Research 12, 54-81.

Hede, A.-M. (2007), Managing special events in the new era of the triple bottom line, Event Management 11(1/2), 13-22.

Holmes, K. and Ali-Knight, J. (2017), The event and festival life cycle-developing a new model for a new context, International Journal of Contemporary Hospitality Management 29(3), 986-1004.

Holmes, K., Hughes, M., Mair, J., and Carlsen, J. (2015), Events and Sustainability, Routledge, London.

Jimura, T. (2018), World Heritage Sites: Tourism, Local Communities and Conservation Activities, Wallingford, CABI.

Karakadis, K. and Kaplanidou, K. (2012), Legacy perceptions among host and non-host Olympic Games residents: A longitudinal study of the 2010 Vancouver Olympic Games, European Sport Management Quarterly 12(3), 243-264.

Kim, S. and Dombrosky, J. (2016), Economic impact of small scale event to the local economy: Case of Canfield Fair, Journal of Tourism Insights 7(1), 1-10.

Lindblom, J., Vogt, C., and Andereck, K. (2020), Construal level theory as a framework for navigating community contexts in tourism planning, Tourism Planning and Development, www.tandfonline.com/doi/abs/10.1080/21568316.2020.18552381-19

Ludvigsen, J.A.L. and Hayton, J.W. (2020), Toward Covid-19 secure events: Considerations for organizing the safe resumption of major sporting events, Managing Sport and Leisure, https://doi.org/10.1080/23750472.2020.1782252

Maguire, K. (2019), Examining the power role of local authorities in planning for socio-economic event impacts, Local Economy 34(7), 657-679.

Maguire, K. (2020), An examination of the level of local authority sustainable planning for event management: A case study of Ireland, Journal of Sustainable Tourism, https://doi.org/10.1080/09669582.2020.1828431

Maguire, K. and McLoughlin, E. (2019), An evidence informed approach to planning for event management in Ireland, Journal of Place Management and Development 13(1), 47-72. 
Maharaj, B. (2015), The turn of the south? Social and economic impacts of mega-events in India, Brazil and South Africa, Local Economy 30(8), 983-999.

Maharaj, B. (2017), Contesting displacement and the struggle for survival: The case of subsistence fisher folk in Durban, South Africa, Local Economy 32(7), 744-762.

Mair, J. (2011), Events and climate change: An Australian perspective, International Journal of Event and Festival Management 2(3), 245-253.

Mair, J. (ed.) (2019). The Routledge Handbook of Festivals, Routledge, London.

Misener, L. and Lu, L.D. (2020), Changing parasport landscape and the evolution of the International Paralympic Committee governance, in Yamamoto, M.Y., Seguin, B., Garcia, B., and Chatziefstathiou, D. (eds), Routledge Handbook on the Olympic and Paralympic Games, Routledge, London, 217-228.

Misener, L. and Wasser, K. (2016), International sport development, in Sherry, E., Schulenkorf, N., and Phillips, P. (eds), Managing Sport Development: An International Approach, Routledge, London, 31-41.

Misener, L., Lu, L.D., and Carlisi, R. (2020), Leveraging events to develop collaborative partnerships: Examining the formation and collaborative dynamics of the Ontario Parasport Legacy Group, Journal of Sport Management 34(5), 447-461.

Mooney, G., McCall, V., and Paton, K. (2015), Exploring the use of large sporting events in the post-crash, post-welfare city: A "legacy" of increasing insecurity?, Local Economy 30(8), 910-924.

Musgrave, J. and Raj, R. (2009), Introduction to a conceptual framework for sustainable events, in Raj, R. and Musgrave, J. (eds), Event Management and Sustainability, CABI, Cambridge, MA, 1-12.

Parnell, D., Widdop, P., Bond, A., and Wilson, R. (2020), Covid-19, networks and sport, Managing Sport and Leisure, https://doi.org/10.1080/23750472.2020.1750100

Preuss, H. (2007a), The conceptualisation and measurement of mega sport event legacies, Journal of Sport and Tourism, 12(3/4), 207-228.

Preuss, H. (2007b), The Impact and Evaluation of Major Sporting Events, Routledge, London.

Richards, G. (2017), From place branding to placemaking: The role of events, International Journal of Event and Festival Management 8(1), 8-23.

Richards, G. and Marques, L. (2016), Bidding for success? Impacts of the European Capital of Culture bid, Scandinavian Journal of Hospitality and Tourism 16(2), 180-195.

Roberts, P. (2017), The evolution, definition and purpose of urban regeneration, in Roberts, P., Sykes, H., and Granger, R. (eds), Urban Regeneration (2nd Edition), SAGE, London, 9-43.

Rojek, C. (2013), Event Power: How Global Events Manage and Manipulate, SAGE, London.

Sadd, D. (2010), What is event-led regeneration? Are we confusing terminology or will London 2012 be the first games to truly benefit the local existing population?, Event Management 13(4), 265-275.

Smith, A. (2012), Events and Urban Regeneration: The Strategic Use of Events to Revitalise Cities, Routledge, London.

Smith, A. and Fox, T. (2007), From "event-led" to "event-themed" regeneration: The 2002 Commonwealth Games legacy programme, Urban Studies 44(5/6), 1125-1143.

Tian, E. (2017), China's "G-7 revolution" in soccer, International Journal of the History of Sport 34(17/18), 1915-1932. 
Tian, E. and Wise, N. (2020), An Atlantic divide? Mapping the knowledge domain of European and North American-based sociology of sport, 2008-2018, International Review for the Sociology of Sport 55(8), 1029-1055.

Ulian, F. and da Silva, R.B. (2020), Using mobile methods to analyze physical activity in the District of Itaquera, São Paulo, Brazil, Sport in Society 23(1), 24-39.

van der Steen, T. and Richards, G. (2019), Factors affecting resident support for a hallmark cultural event: The 2018 European Capital of Culture in Valletta, Malta, Journal of Policy Research in Tourism, Leisure and Events, https://doi.org/10.1080/ 19407963.2019.1696352

Van Niekerk, M. (2017), Contemporary issues in events, festivals and destination management, International Journal of Contemporary Hospitality Management 29(3), 842-847.

Waitt, G. (2003), Social impacts of the Sydney Olympics, Annals of Tourism Research $30(1), 194-215$.

Wise, N. (2019), Towards a more enabling representation: Framing an emergent conceptual approach to measure social conditions following mega-event transformation in Manaus, Brazil, Bulletin of Latin American Research 38(3), 300-316.

Wise, N. (2020a), Eventful futures and triple bottom line impacts: BRICS, image regeneration and competitiveness, Journal of Place Management and Development 13(1), 89-100.

Wise, N. (2020b), Urban and rural event tourism and sustainability: Exploring economic, social and environmental impacts, Sustainability 12(14), 5712.

Wise, N. and Harris, J. (eds) (2017), Sport, Events, Tourism and Regeneration, Routledge, London.

Wise, N. and Harris, J. (eds) (2019), Events, Places and Societies, Routledge, London.

Wise, N., Flinn, J., and Mulec, I. (2015), Exit festival: Contesting political pasts, impacts on youth culture and regenerating the image of Serbia and Novi Sad, in Moufakkir, O. and Pernecky, T. (eds), Wallingford, CABI, 60-73.

Wise, N., Đurkin Badurina, J., and Perić, M. (2021), Assessing residents' perceptions of urban placemaking prior to hosting a major cultural event, International Journal of Event and Festival Management 12(1), 51-69.

Wise, N., Perić, M., and Đurkin, J. (2019), Benchmarking service delivery for sports tourism and events: Lessons for Gorski Kotar, Croatia from Pokljuka, Slovenia, European Journal of Tourism Research 22, 107-128.

Zhao, Y. and Wise, N. (2019), Evaluating the intersection between "green events" and sense of community at Liverpool's Lark Lane Farmers Market, Journal of Community Psychology 47(5), 1118-1130.

Ziakas, V. (2019), Issues, patterns and strategies in the development of event portfolios: Configuring models, design and policy, Journal of Policy Research in Tourism, Leisure and Events 11(9), 121-158.

Ziakas, V. and Costa, C. (2011), The use of an event portfolio in regional community and tourism development: Creating synergy between sport and cultural events, Journal of Sport and Tourism 16(2), 149-175. 
Nicholas Wise - 9781839109256 Downloaded from PubFactory at 04/26/2023 03:06:51PM via free access 